\title{
Sorologia e histopatologia de Toxoplasma gondii e Neospora caninum em cães portadores de distúrbios neurológicos ${ }^{1}$
}

\section{Serology and histopathology of Toxoplasma gondii and Neospora caninum in dogs with neurologic disorders}

\author{
Jamile Haddad Giraldi²; Ana Paula Frederico Rodrigues Loureiro Bracarense ${ }^{3 *}$; \\ Odilon Vidotto ${ }^{3}$; Eduardo Alberto Tudury ${ }^{4}$; \\ Italmar Teodorico Navarro ${ }^{3}$; Thiago Neves Batista ${ }^{5}$
}

\section{Resumo}

Neste trabalho estudou-se a participação do Toxoplasma gondii e Neospora caninum na etiologia de sinais neurológicos em cães. Foram utilizados 98 cães com distúrbios neurológicos provenientes da área urbana divididos em dois grupos: Grupo I constituído de 67 animais atendidos no período de 1987 a 1990 pelo Serviço de Neurologia Animal da Universidade Estadual de Londrina, onde se utilizaram os tecidos emblocados em parafina e Grupo II com 31 animais atendidos no período de 2000 a 2001 nesta mesma instituição. Os animais foram avaliados sorologicamente para pesquisa de anticorpos contra $T$. gondii e $N$. caninum. Os resultados da sorologia para $T$. gondii obtidos no grupo I e II foram $82,5 \%$ e $35.4 \%$, respectivamente. Foram observadas lesões histológicas compatíveis com cinomose nos dois grupos. Cistos de T. gondii foram diagnosticados em dois cães através da histopatologia e imuno-histoquímica. A neosporose não foi diagnosticada em nenhum animal, provavelmente devido à procedência urbana dos animais estudados.

Palavras chave: Neospora caninum, Toxoplasma gondii, sistema nervoso, cães, imuno-histoquímica.

\begin{abstract}
The evolvement of Toxoplasma gondii and Neospora caninum on etiology of clinical-neurological signs in dogs was investigated in this work. Ninety-eight urban dogs with neurologic disturbances were divided into two groups: Group I consisted of 67 dogs examined by the Animal Neurologic Service of Universidade Estadual de Londrina, between 1987 and 1990. Group II consisted of 31 dogs examined on the same University between 2000 and 2001. Dogs were serological evaluated for evidence of $T$. gondii or N. caninum. The serological results for T. gondii were $82,5 \%$ and $35.4 \%$ on groups I and II, respectively. Histologic lesions compatible with distemper on the two groups were observed. T. gondii cysts were observed in two dogs by histopathology and immunohistochemistry. Neosporosis was not observed in these dogs, possibly because their urban origin.

Key words: Neospora caninum, Toxoplasma gondii, nervous system, dogs, immunohistochemistry.

\footnotetext{
${ }^{1}$ Trabalho financiado pelo CNPq, CAPES e CPG-UEL

${ }^{2}$ Aluna do Programa de Pós-graduação em Ciência Animal (área de concentração: Sanidade Animal; nível: mestrado), Universidade Estadual de Londrina (UEL). E-mail: jamile.giraldi@prof.unopar.br

${ }^{3}$ Prof. Dr. do Depto de Med. Vet. Prev. da UEL Caixa Postal 6001, CEP 86051-990, Londrina-PR.

${ }^{4}$ Prof. Dr. do Depto de Clínicas Vet. da Universidade Federal Rural de Pernambuco.

${ }^{5}$ Médico Veterinário, residente do Hospital Veterinário da UEL.

* Autor para correspondências. Email: anapaula@uel.br
} 


\section{Introdução}

Distúrbios neurológicos em cães podem ter origens congênitas, metabólicas, tóxicas, nutricionais, traumáticas, vasculares, degenerativas, neoplásica, idiopática e inflamatório-infecciosa. A cinomose, uma das doenças neurológicas mais comuns em cães, apresenta lesões e sinais clínico-neurológicos extremamente variáveis (CHRISMAN, 1991). O diagnóstico histopatológico pode ser sugerido pelo achado de corpúsculos de inclusão no sistema nervoso (WHEELER, 1995).

Doenças neurológicas causadas por protozoários são pouco comuns nesta espécie. A maioria dos casos descritos é atribuída ao Toxoplasma gondii, cujos sinais variam conforme a localização da lesão no sistema nervoso (HASS; SHELL; SUNDERS, 1989). A prevalência aumenta com a idade, pois a chance de exposição eleva-se proporcionalmente. A toxoplasmose clínica em cães geralmente está associada ao vírus da cinomose ou outras infecções, como erliquiose, ou com terapia imunossupressora. Em alguns casos, contudo, os fatores predisponentes não são identificados. Historicamente, a prevalência da toxoplasmose tem diminuído com o uso de vacinas contra cinomose (DUBEY; LAPPIN, 1998).

Recentemente, outro protozoário, o Neospora caninum, passou a ser reconhecido como causador de afecções neuromusculares, miocárdicas, pulmonares e dérmicas. Apesar da semelhança com a toxoplasmose, os sinais neurológicos e a miosite são mais frequientes na neosporose. Enquanto o T. gondii está associado com infecções intercorrentes, o $N$. caninum parece ser um patógeno primário (LE COUTEUR; GRANDY, 2000). O diagnóstico diferencial entre $N$. caninum e $T$. gondii pode ser feito pela microscopia eletrônica, imuno-histoquímica e PCR (DUBEY; LAPPIN, 1998).

O objetivo deste trabalho foi avaliar a ocorrência do $N$. caninum e $T$. gondii, através da sorologia e histopatologia, em cães portadores de distúrbios neurológicos.

\section{Material e métodos}

Foram examinadas amostras de soro, líquor e de fragmentos de tecidos de cães urbanos com distúrbios neurológicos atendidos no Hospital Veterinário (HV) da Universidade Estadual de Londrina (UEL) e clínicas particulares da região Norte do Estado do Paraná. Dois grupos de animais foram constituídos: Grupo I - 67 cães (35 machos e 32 fêmeas) que foram submetidos a exame clínico-neurológico no período de 1987 a 1990. A idade destes animais variou de três meses a 10 anos, com maior ocorrência de sinais neurológicos entre um e quatro anos; Grupo II - 31 cães (16 fêmeas e 15 machos) atendidos pelo serviço de neurologia do HV, entre janeiro de 2000 e janeiro de 2001. Os animais deste grupo tinham entre dois meses e sete anos de idade, com a maior ocorrência de sinais neurológicos entre cinco e nove meses. Os sinais neurológicos mais comuns nos animais do grupo I foram: mioclonia em 37 cães $(67.27 \%)$, paresia em $24(43.63 \%)$, ataxia em 9 (16.36\%) e convulsão em 8 (14.54\%). No grupo II, $14(45.15 \%)$ apresentaram mioclonias, $8(25.80 \%)$ convulsões e $7(22.58 \%)$ ataxia. Todos os animais foram submetidos à eutanásia por indicação de Médico Veterinário, devido ao prognóstico ruim a desfavorável dos distúrbios apresentados.

Antes de serem sacrificados, amostras de soro e líquor foram obtidas dos animais dos dois grupos, para a pesquisa de anticorpos anti-T. gondii pela técnica da IFI (CAMARGO, 1964), considerando-se como ponto de corte a diluição de 1:16. O controle positivo foi obtido a partir de soro de um cão inoculado experimentalmente, apresentando título previamente conhecido de 4096. O controle negativo foi obtido a partir de soro canino isento de anticorpos anti-T. gondii. Como conjugado utilizou-se imunoglobulinas de coelho anti-IgG de cão marcadas com isotiocianato de fluoresceína (Sigma). As amostras de soro dos cães do grupo II também foram submetidas a IFI para pesquisa de anticorpos anti- $N$. caninum, de acordo com a técnica descrita por Conrad et al. (1993), utilizando-se como ponto de corte a diluição 1:50. As lâminas com antígeno, os controles negativo e positivo de soro canino e o conjugado anti-IgG canino foram adquiridos do laboratório VMRD Inc., Pullman, EUA e utilizados de acor- 
do com as recomendações do fabricante. Para que uma reação fosse considerada positiva, na diluição do ponto de corte ou final, tanto para T. gondii como para $N$. caninum, os taquizoítas tinham que apresentar fluorescência periférica total (PARÉ, 1995).

Após a eutanásia os animais foram submetidos à necropsia. As lesões macroscópicas foram anotadas. Amostras de cérebro, cerebelo, fígado, pulmão, músculo esquelético, coração, bexiga, rins e eventualmente medula espinhal foram colhidas e fixadas em formalina tamponada $10 \%$ durante $48-72$ horas. O material foi processado de acordo com a técnica histológica e emblocado em parafina. Cortes de cinco $\mu \mathrm{m}$ de espessura foram incorporados em lâminas e corados pelo método de Hematoxilina-Eosina (HE) para leitura em microscópio óptico. As lesões histológicas foram registradas e classificadas de modo a triar os animais a serem submetidos a imunohistoquímica. Gliose, malácia, meningoencefalite não supurativa, miosite e miocardite foram consideradas lesões sugestivas da neosporose e/ou toxoplasmose.

O método imuno-histoquímico utilizado para marcação do $N$. caninum foi o da avidina-biotinaperoxidase (Dako Corp., EUA) e para o T. gondii o método do polímero marcado (Envision-Dako Corp., EUA). Como anticorpos primários utilizou-se antiN. caninum (VRMD - Pullman EUA) na diluição de 1:1500 e anti-T. gondii (DAKO Corp., EUA), sem diluição prévia. Os anticorpos secundários biotinilados foram diluídos e aplicados de acordo com a recomendação do fabricante. A revelação da marcação foi feita com solução de diaminobenzidina (DAB) a $0,1 \%$ (DAKO Corp. EUA). Como controle positivo utilizou-se corte de cérebro de camundongo inoculado experimentalmente, contendo cistos de T. gondii. Para o N. caninum utilizaram-se fragmentos de medula espinhal e cérebro de bezerro que apresentavam cistos do parasita. Reações de cor castanho dourado ou marrom, presente nas lesões, nos cistos ou nos taquizoítos foram consideradas positivas para ambos os coccídios. Todos os animais do grupo II foram submetidos ao exame imunohistoquímico para ambos os protozoários. Nos animais do grupo I, esta técnica foi realizada apenas nos cães que apresentavam lesões histológicas sugestivas de neosporose ou toxoplasmose.

\section{Resultados}

$\mathrm{Na}$ Tabela 1 podem ser visualizados os percentuais de animais soropositivos para $T$. gondii pela IFI. Os títulos de anticorpos mais freqüentes encontrados nos soros dos animais do Grupo I foram de 64 (13), 256 (12) e 4096 (11) e no Grupo II 16 (8), 64 (1) e 256 (2). O exame do líquor evidenciou cinco animais soropositivos no Grupo I com títulos de 16 e 64 e nenhum no Grupo II. Os títulos sorológicos para T. gondii indicativos de infecção crônica ou aguda em ambos os grupos estão demonstrados na Tabela 2. Nenhum soro, das amostras examinadas do Grupo II, reagiu para antígenos de $N$. caninum, pela IFI.

Tabela 1 - Ocorrência de anticorpos contra Toxoplasma gondii em soros de cães com distúrbios neurológicos, pela técnica de imunofluorescência Indireta (IFI).

\begin{tabular}{cccc} 
Animais & \multicolumn{3}{c}{ I F I } \\
\cline { 2 - 4 } & Positivo (\%) & Negativo (\%) & Total \\
\cline { 2 - 4 } Grupo I & $52(82,5)$ & $15(17,5)$ & 63 \\
GrupoII & $11(35,4)$ & $20(64,5)$ & 31 \\
\hline Total & 63 & 31 & 94 \\
\hline$* \mathrm{p}<0,001$ & & &
\end{tabular}

Tabela 2 - Títulos sorológicos para Toxoplasma gondii observados em cães com distúrbios neurológicos.

\begin{tabular}{lcc}
\hline & \multicolumn{2}{c}{ Título sorológico } \\
\cline { 2 - 3 } Animais & $<4096$ & $\geq 4096$ \\
\hline Grupo I & 39 & 13 \\
Grupo II & 11 & 0 \\
\hline TOTAL & 50 & 13 \\
\hline * $\mathrm{p}=0,1004$ (teste exato de Fischer)
\end{tabular}


Ao exame macroscópico, observou-se, nos dois Grupos, congestão dos vasos superficiais cerebrais, palidez hepática, edema, congestão e enfisema pulmonar. No Grupo II a esplenomegalia foi um achado freqüente.

Em ambos os grupos as lesões microscópicas observadas com maior frequiência no tecido nervoso foram: manguitos perivasculares, meningite crônica, gliose focal, malácia em substância branca e corpúsculos de Lenz em células da glia e neurônios. A cinomose foi diagnosticada pela presença dos corpúsculos de inclusão viral associada à malácia, espongiose, manguitos perivasculares e gliose. A ocorrência da doença nos grupos I e II foi de $67.16 \%$ e $54.83 \%$, respectivamente.

No grupo I constatou-se encefalite, mielite crônica e malácia associadas a cistos de protozoários em dois animais (3\%). O exame imuno-histoquímico destes cortes teciduais demonstrou marcação para $T$. gondii (Figura 1). Um dos animais apresentou título de 64 no soro e título negativo no líquor para $T$. gondii.

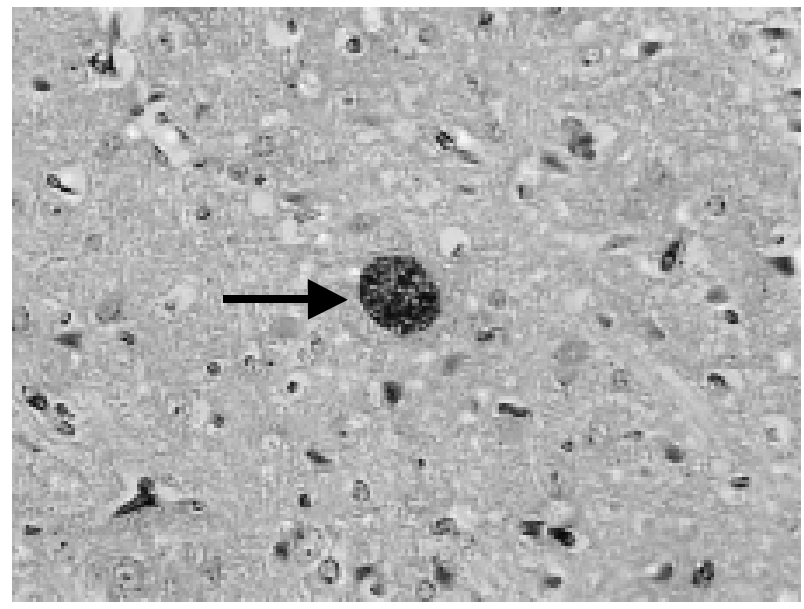

Figura 1 - Fotomicrografia de cérebro de cão contendo cisto de Toxoplasma gondii (seta), marcado pela técnica de imuno-histoquímica (40X).

No grupo II, oito animais (22.58\%) apresentaram meningite crônica associada a infiltrado plasmocitário intersticial renal e glomerulonefrite membrano-proliferativa. Cistos de Sarcocystis sp foram verificados em fragmentos de tecido cardíaco e músculo esquelético de um cão. Estes cortes não apresentaram marcação tecidual no exame imunohistoquímico. Dois animais $(6.45 \%)$ apresentaram miosite. Não foram observados cistos ou taquizoítos de $T$. gondii ou $N$. caninum no exame imunohistoquímico do tecido nervoso. Os dois grupos de animais apresentaram pneumonia intersticial, degeneração vacuolar de hepatócitos e histiocitose de linfonodos. Ausência de lesões foi constatada em $17.91 \%$ dos animais do grupo I e $12.90 \%$ dos animais do grupo II.

\section{Discussão}

A faixa etária dos animais pesquisados variou de dois meses a 10 anos. De acordo com a literatura consultada, doenças neurológicas como cinomose (GREENE; APPEL, 1998), toxoplasmose (DUBEY; LAPPIN, 1998) e neosporose (BARBER, 1998) podem acometer cães de qualquer idade.

Enquanto 77,6\% dos animais do Grupo I foram positivos para a presença de anticorpos anti-T. gondii, no Grupo II apenas $35.4 \%$ foram soropositivos. A ausência de amostras pareadas de soro não permitiu evidenciar casos de infecção ascendente. Estas taxas de sororreagentes são semelhantes às observadas, em diferentes épocas e regiões do Brasil, por Ishizuka e Yasuda (1974), Germano, Erbolato e Ishizuka (1985) e Guimarães, Ribeiro e Lima (1992). Considerando que os animais estudados eram provenientes de uma mesma região e a diferença de período entre os dois grupos estudados é de 10 anos, é possível que a diminuição expressiva de animais sororreagentes observada entre os dois grupos esteja associada a fatores como o aumento do consumo de ração, maior utilização de vacina contra cinomose e melhor nível de educação sanitária aos proprietários.

A Tabela 2 revela uma maior percentagem de títulos sorológicos indicativos de infecções crônicas $(<4096)$ do que agudas (> 4096) para T. gondii. Embora a diferença entre os grupos não seja estatisticamente significativa, é previsível o encontro de títulos baixos nos animais portadores de cinomose, associado ao encontro de cistos teciduais na 
histopatologia (BRITO, 1999).

A sorologia do líquor não mostrou resultados consistentes para diagnosticar a toxoplasmose nervosa. De acordo com Hass, Shell e Sunders (1989), os baixos títulos de anticorpos no líquor podem ser decorrentes da barreira hemato-encefálica, que impede a entrada de anticorpos no sistema nervoso central, tornando essa modalidade de exame de pouco valor diagnóstico.

A ausência de animais sorroreagentes para $N$. caninum entre as amostras pesquisadas pode ser explicada pela procedência dos animais estudados que eram todos cães urbanos. De acordo com Wouda (1999), a prevalência de anticorpos contra $N$. caninum é significativamente maior em cães provenientes de áreas rurais, em comparação com cães de áreas urbanas ou provenientes de clínicas. Aparentemente, cães rurais têm um risco de exposição maior ao $N$. caninum do que os urbanos. Observações semelhantes foram feitas no Japão por Sawada (1998), baseadas em estudo comparativo entre 48 cães da área rurais e 198 cães da área urbana. Uma possível explicação para a alta prevalência de infecção por $N$. caninum em cães da área rural reside no fato destes animais mostrarem comportamento mais evidente de carnivorismo, ingerindo pequenos mamíferos e aves que porventura contenham cistos de N. caninum (WOUDA, 1999).

Comparada à sorologia, a técnica de imunohistoquímica não é suficientemente sensível para o diagnóstico da toxoplasmose; desta forma, esta técnica seria mais indicada para a confirmação do agente em casos clínicos sugestivos de toxoplasmose (ROSA, 1999). Contudo, a histopatologia e a imunohistoquímica não devem ser desprezadas, pois são úteis para revelar a presença e o grau das lesões encontradas e tornar possível a diferenciação entre $T$. gondii e N. caninum, respectivamente. Adicionalmente, o encontro de cistos ou taquizoítas pela coloração de $\mathrm{HE}$ ou pela técnica de imuno-histoquímica vai depender se determinado fragmento escolhido contém as referidas formas evolutivas, o que nem sempre acontece. Um completo exame neurológico do animal com o objetivo de localizar a lesão no sis- tema nervoso associado à utilização de vários fragmentos de tecidos na análise histopatológica e ou imuno-histoquímica contribui para o aumento da sensibilidade destas técnicas.

O sinal clínico mais freqüente apresentado pelos animais de ambos os grupos foi a mioclonia. Embora considerada um sinal específico da infecção pelo vírus da cinomose, a mioclonia também pode ser observada em outras infecções causadas por paramyxovírus de cães e gatos e, mais raramente, em outras condições inflamatórias do sistema nervoso central (TIPOLD, 1995). A mioclonia pode às vezes ser confundida com um padrão de convulsão, onde há sintomas motores tais como a contração ou flexão rítmica de um membro específico, ocorrendo de modo repetitivo, convulsão após convulsão (BERENDT; GRAM, 1999).

A cinomose não deve ser diagnosticada apenas pela presença isolada de corpúsculos de inclusão (GREEN; APPEL, 1998). Contudo, as inclusões observadas neste trabalho não estiveram isoladas, mas associadas à espongiose, gliose e malácia, o que constitui forte indicativo da presença do vírus da cinomose nos cães estudados.

Campbell, Mackay e Vantsis (1958), Capen e Cole (1966) e Ehrensperger e Popischil (1989) verificaram que a toxoplasmose clínica está associada ao vírus da cinomose em taxas de 5.9\%, 40\% e 54\%, respectivamente. No entanto, Hass, Shell e Sunders (1989) observaram que a toxoplasmose não esteve associada à cinomose ou outras infecções intercorrentes. Resultados semelhantes foram constatados neste trabalho. Os dois animais que apresentaram cistos de $T$. gondii não tinham lesões compatíveis com cinomose, enquanto nos animais que apresentaram lesões compatíveis com cinomose a infecção por protozoários esteve ausente.

\section{Referências}

BARBER, J. S. Neosporosis canina. Waltham Focus, London, v.8, p.25-29, 1998. 
BERENDT, M.; GRAM, L. Epilepsy and seizure classification in 63 dogs: a reappraisal of veterinary epilepsy terminology. Journal of Veterinary Internal Medicine, Lawrence, v. 13, p. 14-20, 1999.

BRITO, A. J. Avaliação epidemiológica e título sorológico anti-Toxoplasma gondii em cães com sintomatologia nervosa. 1999. Dissertação (Mestrado) - Faculdade de Medicina veterinária e Zootecnia, Universidade Estadual Paulista, Botucatu.

CAMARGO, M. E. Improved technique of indirect immunofluorescence for serological diagnosis of toxoplasmosis. Revista do Instituto de Medicina Tropical de São Paulo, São Paulo, v.6, p.117-118, 1964.

CAMPBELL, R. S. F.; MACKAY, J. M. K.; VANTSIS, J. T. Canine toxoplasmosis: the isolation of Toxoplasma gondii from a dog. Journal of Comparative Pathology, London, v.68, p.96-105, 1958.

CAPEN, C. C.; COLE, C. R. Pulmonary lesionss in dogs with experimental and naturally occuring toxoplasmosis. Veterinary Pathology, Lawrence, v.3, p.40-63, 1966.

CHRISMAN, C. L. Problems in small animal neurology. $2^{\text {th }}$ ed. Philadelphia: Lea \& Fabiger, 1991.

CONRAD, P. A. et al. In vitro isolation and characterization of a Neospora sp from aborted bovine foetuses. Parasitology, Cambridge, v. 106, p. 239-249, 1993.

DUBEY, J. P., LAPPIN, M. R. Toxoplasmosis and Neosporosis. In: GREEN, G. G. (Ed.). Infectious diseases of the dog and cat. $2^{\text {th }}$ ed. Philadelphia: Saunders, 1998. Cap.80, p.493-509.

EHRENSPERGER, F.; POSPISCHIL, A. Spontaneous mixed infection with distemper virus ant Toxoplasma in dogs. Deutsche Tieraztliche Wochenschrift, Hannover, v. 96, p.184-186, 1989.

GERMANO, P. M. L.; ERBOLATO, E. B.; ISHIZUKA, M. M. Estudo sorológico da toxoplasmose canina, pela prova de imunofluorescência indireta na cidade de Campinas. Arquivo Brasileiro de Medicina Veterinária e Zootecnia, Belo Horizonte, v.22, p.53-58, 1985.

GUIMARÃES, A. M.; RIBEIRO, M. F. B.; LIMA, J. D. Frequiência de anticorpos anti-Toxoplasma em cães de Belo Horizonte, MG. Arquivo Brasileiro de Medicina Veterinária e Zootecnica, Belo Horizonte, v.44, p.67-68, 1992.
GREENE, C. E.; APPEL, M. J. Canine Distemper. In: GREENE, C. E. Infectious diseases of the dogs and cats. 2.ed. Philadelphia: Saunders, 1998. Cap.3, p.9-22.

HASS, J. A.; SHELL, L.; SUNDERS, G. Neurologic manifestations of toxoplasmosis: a literature review and case summary. Journal of American Animal Hospital Association, Lakewood, v.5, p.253, 1989.

ISHIZUKA, M. M.; YASUDA, P .H. Prevalência de anticorpos anti-toxoplasma em soros de cães do município de São Paulo. Revista da Faculdade de Medicina Veterinária e Zootecnia da Universidade de São Paulo, São Paulo, v.11, p.115-125, 1974.

LeCOUTEUR, R. A.; GRANDY, J. L. Diseases of the spinal cord. IN: ETTINGER, J. P. (Ed.). Textbook of veterinary internal medicine. $5^{\text {Th }}$ ed. Philadelphia: Saunders, 2000. Cap. 106, p.608-657.

PARÉ, J.; HIETALA, S. K.; THURMOND, M. C. Interpretation of na indirect fluorescent antibody test for diagnosis of Neospora sp infection in cattle. Journal of Veterinary Diagnostic Investigation, Columbia, v.7, p.273-275, 1995.

ROSA, C. Avaliação da toxoplasmose experimental em caprinos pelas provas de bioensaio em camundongos $e$ imuno-histoquímica, 1999. Dissertação (Mestrado) Faculdade de Medicina Veterinária e Zootecnica da Universidade de São Paulo, São Paulo.

SAWADA, M. Serological survey of antibody to Neospora caninum in japanese dogs. Journal of Veterinary Medical Science, Tokyo, v.60, p.853-854, 1998.

TIPOLD, A. Diagnosis of inflamatory and infectious diseases of the central nervous system in dogs: a retrospective study. Journal of Veterinary Internal Medicine, Philadelphia, v.9, p.304, 314, 1995.

WHEELER, S. J. Manual of small animal neurology. Gloucestershire: British Small Animal Veterinary Association. 1995.

WOUDA, W. et al. Seroepidemiological evidence for a relationship between Neospora caninum infections in dogs and cattle. International Journal for Parasitology, Elmsford, v.29, p. 1677-1682, 1999. 